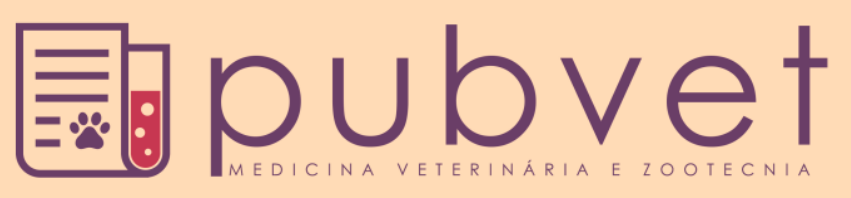

HTTP://DX.DOI.ORG/10.22256/PUBVET.V11N12.1210-1219

\title{
Fungos de armazenagem e micotoxinas em dieta para ovinos (Ovis aries L.): estudo de caso
}

\section{Carlos Eduardo da Silva Soares ${ }^{1 *}$, Camila Siedlarczyk Martins ${ }^{2}$, Giovana Sousa Maria ${ }^{3}$, Vildes Maria Scussel ${ }^{4}$}

${ }^{I}$ Mestrando em Ciência e Tecnologia de Alimentos, Federal de Santa Catarina - UFSC-Florianópolis, SC, Brasil c.ess@posgrad.ufsc.br ${ }^{2}$ Graduanda em Ciência e Tecnologia de Alimentos, Federal de Santa Catarina - UFSC - Florianópolis, SC, Brasil.camila.sied@gmail.com

${ }^{3}$ Graduanda em Ciência e Tecnologia de Alimentos, Federal de Santa Catarina - UFSC - Florianópolis, SC, Brasil.giovana.maria.gsm@gmail.com

${ }^{4}$ Professora Dra. Departamento de Ciência e Tecnologia de Alimentos - UFSC-Florianópolis, SC, Brasil. vildescussel_2000@yahoo.co.uk

*Autor para correspondência: Laboratório de Micotoxicologia e Contaminantes de Alimentos - LABMICO. Ciência e Tecnologia de Alimentos, Centro de ciências agrarias, Universidade Federal de Santa Catarina, Rod Admar Gonzaga 1346, Itacorubi, Florianópolis, SC, Brasil.

RESUMO. Fungos e suas condições de armazenagem (umidade) e a contaminação por micotoxinas em alimentos oferecidos para ovinos foram avaliados. Animais da raça crioula criados na Fazenda Ressacada-UFSC e com saúde debilitada. Com as amostras de (a) feno de alfafa (Medicago sativa L.) estavam armazenadas em 3 pontos (entrada do galpão, aprisco e sala), além de (b) pastagem (B. decumbens) obtida no campo e (c) ração (milho e soja) armazenada no aprisco. O gênero fúngico mais detectado foi o Aspergillus, seguido do Penicillium em 75 e $40 \%$ das amostras, respectivamente. Cepas toxigênicas (produtoras de AFLs) foram identificadas. Quanto a umidade ( $\mathrm{mc}$ e aw) os teores variaram entre 1240\% (média:12\%) e $\mathrm{a}_{\mathrm{w}}$ : 0,5029-0,9888 (média: 0,5783), considerado adequado para proliferação de fungos. Das micotoxinas avaliadas (aflatoxinas - $\mathrm{AFL}_{\mathrm{s}}$, ocratoxina $\mathrm{A}$ OTA, zearalenona - ZON e esterigmatoscistina - EST), as de armazenagem (AFLs: $\mathrm{AFB}_{1}$, $\mathrm{AFB}_{2}, \mathrm{AFG}_{1}, \mathrm{AFG}_{2}$ ) foram detectadas com teores de $128 \mu \mathrm{g} / \mathrm{kg}$ nas amostras de feno. As condições de limpeza (armazém e maquinários) são de extrema importância, uma vez que as amostras recém-chegadas ao local de abrigo das ovelhas se encontram contaminadas.

Palavras chave: Alfafa, feno, micotoxinas, multitoxinas, pasto, ração

\section{Storage fungi and mycotoxins in sheep diet (Ovis aries L.): a case study}

ABSTRACT. Fungi and their storage conditions (moisture) and contamination by mycotoxins in foods offered to sheep were evaluated. Crioula animals created at Farm Ressacada - UFSC and with weakened health. The samples of alfalfa hay (Medicago sativa L.) were stored at 3 points (entrance of the shed, sheepfold and room), besides (b) pasture (B. decumbens) obtained in the field and (c) ration (Corn and soybean) stored in the sheepfold. The most detected fungal genus was Aspergillus, followed by Penicillium in 75 and $40 \%$ of the samples, respectively. Toxigenic strains (AFLs producers) were identified. As regards moisture ( $\mathrm{mc}$ and aw) the contents ranged from 12-40\% (mean: 12\%) and aw: 0.5029-0.9888 (mean: 0.5783), considered adequate for fungal growth. Mycotoxins (AFLs: AFB1, AFB2, AFG1, AFG2) were detected at levels of $128 \mu \mathrm{g} / \mathrm{kg}$ in the hay samples. Cleaning conditions (warehouse and machinery) are of the utmost importance, since samples newly arrived at the shelter of the sheep are contaminated.

Keywords: alfalfa, feed, hay, multitoxins, mycotoxins, pasture 


\title{
Hongos de almacenamiento y micotoxinas en la dieta para ovinos (Ovis aries L.): estudio de caso
}

\begin{abstract}
RESUMEN. Se evaluaron los hongos, las condiciones de almacenamiento (humedad) y la contaminación por micotoxinas en alimentos ofrecidos para ovinos. Animales de raza criolla criados en la Hacienda Resaca-UFSC y con salud debilitada. Con muestras de heno de alfalfa (Medicago sativa L.) que estaban almacenadas en 3 puntos (entrada del galpón, aprisco y sala), además de (b) forraje (B. decumbens) obtenida en el campo y (c) ración (Maíz y soja) almacenada en el aprisco. El género fúngico más detectado fue el Aspergillus, seguido del Penicillium en el 75 y el $40 \%$ de las muestras, respectivamente. Se identificaron cepas toxigénicas (productoras de aflatoxinas). En cuanto a la humedad (mc y aw) los niveles variaron entre el 12-40\% (promedio: 12\%) y aw: 0,5029-0,9888 (promedio: 0,5783 ), considerado adecuado para la proliferación de hongos. En el caso de las micotoxinas evaluadas (aflatoxinas - AFLs, ocratoxina A - OTA, zearalenona - ZON y esterigmatoscistina - EST), las de almacenamiento (AFLS: AFB1, AFB2, AFG1, AFG2) se detectaron con un contenido de $128 \mu \mathrm{g} / \mathrm{kg}$ en las muestras de heno. Las condiciones de limpieza (almacén y maquinaria) son de extrema importancia, ya que las muestras recién llegadas al lugar de refugio de las ovejas se encuentran contaminadas.
\end{abstract}

Palabras clave: Alfalfa, heno, micotoxinas, multitoxinas, pasto, ración

\section{Introdução}

Os esporos são responsáveis pela propagação dos fungos. Os de armazenagem, Aspergillus e Penicillium, por exemplo, em condições favoráveis se desenvolvem com rapidez, durante o processo de cultivo, colheita, transporte e armazenamento (Scussel and Lorini, 2002).

A secagem do feno ocorre à sombra por amontoamento. Tal procedimento proporciona condições ideais para o desenvolvimento de fungos devido à baixa aeração o que dificulta a retirada da umidade (Nascimento et al., 2000). Durante o armazenamento, os fungos (xerófilos) que resistem aos métodos de secagem podem se desenvolver em atividade de água $\left(\mathrm{a}_{\mathrm{w}}\right)$ tão baixa quanto 0,75 , sendo que os toxigênicos a partir de 0,85 tais como os gêneros Aspergillus e Penicillium. Esses progridem e substituem os fungos de campo que são impedidos de se desenvolver ou morrem. Nos grãos, a ação dos fungos é ativada a partir de um limite de $\mathrm{a}_{\mathrm{w}}$ (cerca de 0,72 ) e temperatura de $20^{\circ} \mathrm{C}$ Já, as condições favoráveis de temperatura para produção de toxinas por fungos toxigênicos são $\left(25-35^{\circ} \mathrm{C}\right)$ e mc (13-16\%) (Scussel, 1998, Scussel and Lorini, 2002). Cabe salientar que, os fungos de armazenamento (Aspergillus, Penicillium, incluindo Mucor e Rhizopus) são encontrados nos maquinários agrícolas (moinhos, moegas, elevadores e equipamentos) e no ambiente de armazenamento (armazéns, silos, galpões) (Mallmann et al., 1994).
A presença (ação) do fungo afeta estrutura física dos alimentos, e muitas vezes podem estar presentes seus metabólicos tóxicos. No campo, a contaminação é influenciada pelas condições do ambiente, como umidade relativa do ar, secagem incompleta, umidade do produto, chuvas no período de colheita, insetos, cargas de fungo no solo, ar e sanidade da planta (Fonseca, 2008). Já na armazenagem os fungos, menos exigentes em água, se desenvolvem inclusive os toxigênicos. As micotoxinas são metabolitos produzidos, principalmente por três gêneros fúngicos (Aspergillus, Penicillium e Fusarium) que podem se desenvolver nas forragens (antes, durante e póscolheita) e na armazenagem, desde que fungos patogênicos encontrem condições para seu desenvolvimento. Dentre as micotoxinas mais estudadas são as AFLs, citrinina, tricotecenos, como o DON (deoxinivalenol), fumonisinas, patulina, (OTA) ocratoxina A e (ZON) zearalenona que causam vários danos aos animais (Santos et al., 2014, Iamanaka et al., 2013, Wambacq et al., 2016). As micotoxinas (AFLs, OTA, ZON) são consideradas de risco para os consumidores, tanto animais e quanto humanos (por produtos como leite, ovos, carne e fígado). Os ruminantes são alimentados com feno e pastagem em muitas partes do mundo. As forragens podem ser contaminadas durante seu cultivo no campo ou no momento do armazenamento por várias espécies de fungos micotoxigênico, o que podem aumentar e diversificar o risco de exposição às micotoxinas (Gallo et al., 2015). 
O Grupo de toxinas de armazenagem, as AFLs, comumente encontradas em alimentos provocam graves lesões hepáticas, levando a perdas no desempenho zootécnico. Muitas vezes seus efeitos não são percebidos pelo produtor, pois essas apresentam efeitos subclínicos sobre o metabolismo dos ruminantes (Edrington et al., 1994, Rabassa et al., 2010, Raper and Fennell, 1965).

O objetivo do estudo foi avaliar fungos de armazenagem (carga fúngica, gênero e sua toxigenicidade) e possível contaminação por micotoxinas em alimentos utilizados por ovinos que apresentavam sintomas de debilitação semelhantes à intoxicação por AFLs e ZON.

\section{Material e Métodos}

Amostras: Foram utilizados 3 diferentes tipos de alimentos para ovinos - (a) feno de alfafa (Medicago sativa L.), 10-12\% mc (local de armazenamento: entrada do galpão/aprisco/sala), (b) pasto (Brachiaria decumbens), $40 \% \mathrm{mc}$ e (c) ração propriamente dita (milho \& soja, secos e triturados) $10 \%$ mc. Sendo os principais vegetais responsáveis pela alimentação diária dos ovinos, embora a ração esteja incluída como complemento.

Meios de cultura, reagentes e solventes: (a) meios de cultura: PDA (Potato Dextrose Ágar - PDA Neogen (Michigan, USA), MEA (extrato de malte Ágar) e peptona bacteriológica, Himedia, (Mumbai, Índia); G25N (Czapek-Dox, 25\% de nitrato de glicerol) e CYA (extrato de levedura Czapek), todos Vetec (Duque de Caxias, RJ, Brasil); (b) reagentes: padrões de $\mathrm{AFLs}\left(\mathrm{AFB}_{1}\right.$, $\mathrm{AFB}_{2}, \mathrm{AFG}_{1}$ e $\mathrm{AFG}_{2}$ ), ZON e OTA, todos da Sigma Aldrich (St. Louis, MO, EUA); hidróxido de sódio e potássio, fosfato, cloreto férrico, carbonato de cobre e sulfato de sódio da Merck (Jacarepaguá, RJ, Brasil); ácido acético, Neon (Suzano, SP, Brasil); ácido fórmico e sulfúrico, Biotec (Pinhais, PR, Brasil); cloreto de alumínio e sulfato de sódio anidro, Neon (São Paulo, Brasil), cloreto de potássio, Lafan (Varzea Paulista, SP, Brasil); sulfato de cobre, FMaia, (Belo Horizonte, MG, Brasil) todos de grau analítico; (c) solventes: acetona, Alphatec ( Macaé, RJ, Brasil); etanol, ácido sulfúrico e tolueno, Synth (Diadema, SP,Brasil); sulfato de amônia e benzeno JT Backer, (Center Valley, PA, USA); clorofórmio e acetato de etila, FMaia, (Belo Horizonte, MG, Brasil), metanol, Neon (São Paulo, Brasil); (d) outros -sacarose, glicerina líquida, cloranfenicol, todos da Kyma (Americana, SP, Brasil).

Equipamentos: Câmara de fluxo laminar, Veco (Campinas, SP, Brasil); autoclave vertical, Phoenix (Araraquara, SP, Brasil); cabine bacteriológica, Fanem (São Paulo, SP, Brasil); estufa Quimis (Diadema, SP, Brasil); moinho de laboratório Romer (Miame, USA); balança analítica (faixa 0,01-210 g), Ohaus, (Parsippany, NJ, USA); bomba vácuo Millipore (São Paulo, Brazil); bloco de aquecimento Tecnal (Piracicaba, SP / Brasil); extrator à vácuo, Phenomenex (Torrance, USA); medidor de aw, Aqualab, Decagon (Pullman, Washington, USA); destilador Marconi (São Paulo, Brasil); filtro de água mili-Q Millipore (St. Louis, MO, USA), placa cromatográfica Reagen, Quimibrás (Rio de Janeiro) e microscópio óptico Olympus CX22, (Tokyo, Japão).

Coleta e preparo das amostras: (a) coleta: Foi realizada tanto no local de acomodação dos animais (entrada do galpão, aprisco e sala feno/ração) quanto no campo (piquete - pasto) na Fazenda da Ressacada, Florianópolis - SC). As amostras foram coletadas em porções de $500 \mathrm{~g}$, acondicionadas em sacos de polietileno estéril e envidadas ao Laboratório de Micotoxinas e Contaminantes Alimentares para análises. As amostras de (a.1) feno foram separadas de acordo com o local de armazenagem em (a.1): entrada do galpão (coletada tão logo chegavam) e (a.2) armazenadas em dois locais (aprisco e sala principal). Já o_ (b) capim foi coletado no piquete na mesma quantidade que o feno e (c) ração no mesmo local de (a); (b) preparo das amostras - de (b.1) feno e (b.2) capim, independentemente do tipo armazenagem e/ou umidade, todas foram picadas $(3 \mathrm{~cm})$ com auxílio de uma tesoura esterilizada. Já as amostras de (b.3) ração foram trituradas utilizando moinho Romer. Em seguida as amostras foram pesadas (porções de $50 \mathrm{~g}$ ) para realizar análises de umidade (conteúdo de umidade e atividades água), contagem total de fungos e micotoxinas (AFLs, OTA, ZON, EST). As amostras estavam em fardos, acondicionadas no chão do aprisco e sala com temperatura média de $20^{\circ} \mathrm{C}$.

Micologia: os testes utilizados foram (a) contagem total de fungos - as amostras de feno, pastagem e ração (porções de $25 \mathrm{~g}$ ) foram assepticamente transferidas para sacos de polietileno e adicionadas de água peptonada $(0,1 \%)$, seguido de homogeneização (2 min). De 
cada amostra diluída $\left(10^{-1}, 10^{-2}, 10^{-3}\right)$ um volume de $100 \mu \mathrm{l}$ foi inoculado (na superfície do PDA (contendo cloranfenicol) $(\mathrm{n}=2)$. As placas foram incubadas em estufa $\left(25^{\circ} \mathrm{C} \pm 1^{\circ} \mathrm{C}\right)$ por 7 dias (Silva et al., 2005). Após este período, as colônias desenvolvidas foram enumeradas utilizando contador de colônias e resultado expresso em unidade formadora de colônia por grama (UFC/g); (b) isolamento - as colônias de fungos filamentosos que cresceram no meio PDA foram repicadas assepticamente para os meios MEA, G25N e CYA e incubadas $\left(25^{\circ} \mathrm{C} \pm 1^{\circ} \mathrm{C} / 7\right.$ dias $)$. Após o crescimento das colônias suas características foram observadas macroscopicamente e registradas para auxiliar na identificação (gêneros) (Raper; Fennell, 1965, Pitt, 1979) seguido da (c) identificação dos gêneros fúngicos - pela técnica de microcultivo, que foi realizada em placa de Petri estéril, contendo um suporte de vidro e lâmina com meio de cultura sólido Czapek-doc (área: $5 \mathrm{~cm}$ ), sobre o qual foram acrescentados cubos $( \pm 10 \mathrm{~mm}) \mathrm{de}$ cada colônia isolada em $(b)$ com auxílio de agulha estéril e sobreposta com uma lamínula adicionando algodão contendo água destilada estéril (para manter a umidade) e em seguida será fechada e incubada por 5 dias à $25^{\circ} \mathrm{C} \pm 1^{\circ} \mathrm{C}$. Após este período, a lamínula (contendo parte do crescimento fúngico) foram transferida para outra lâmina contendo uma gota de corante lactofenol azul de algodão e estruturas visualizadas em microscópio óptico $\left[\begin{array}{ll}400 & \mathrm{x}\end{array}\right]$. A partir da observação das características macro e microscópicas, a identificação de gêneros fúngicas foi realizada de acordo com as chaves de identificação de Raper and Fennell (1965) e Pitt (1979).

Micotoxinas: O método utilizado para multitoxinas foi o de Soares and Rodriguez-Amaya (1989). Compreende as etapas de (a) extração foram utilizados metanol como solvente orgânico e solução de cloreto de potássio e limpeza por partição líquido-líquido seguidas de (b) triagem (análise quantitativa) como objetivo de fornecer uma resposta rápida, (c) quantificação e (d) confirmação com solução de ácido sulfúrico. Os limites de detecção (LOD) e quantificação (LOQ) obtidos para o método foram $1 \mu \mathrm{g} / \mathrm{kg}$ e $2 \mu \mathrm{g} / \mathrm{kg}$, respectivamente.

Umidade: (a)teor de umidade- para as análises de umidade das rações $(2 \mathrm{~g})$ foram submetidas a secagem em uma estufa $\left(105 \pm 5^{\circ} \mathrm{C}\right)$ até peso constante através do método gravimétrico de acordo com a AOAC (2005). (b)Atividade da água
- para a determinação do aw, cada amostra (2 g) foi submetida análise $(n=3)$ utilizando $o$ equipamento AquaLab, a $25^{\circ} \mathrm{C}$ (AOAC, 2005).

Sintomas dos animais: Os animais apresentavam fotosensibilidade acompanhada de redução nos dados zootécnicos, prostração, lesões cutâneas, anorexia e severa (pododermatite ou foot rot) crônica, atingindo algumas regiões desprovidas de pelos. A maioria dos animais já apresentaram fotossensibilização em algum determinado período. Os animais foram tratados com homeopatia para reduzir as enfermidades.

\section{Resultados e Discussão}

A partir dos dados obtidos de alimentos (feno, pasto e ração) para ovinos que apresentavam sintomas de debilitação foi possivel observar variações, tanto na carga fungica, gêneros isolados (Aspergillus e Penicillium) quanto em teores de umidade das amostras, inclusive com detecção elevada de AFLs, corroborando os sintomas apresentados pelos ovinos. A Tabela 1 e as Figuras 1-4 apresentam a contaminação por fungos nas diferentes amostras avaliadas, as características das cepas isoladas e a contaminação por micotoxinas.

\section{Fungos de armazenagem isolados da alimentação de ovinos versus condições de umidade}

Para investigar as condições de alimentos utilizados pelos ovinos foram avaliadas a carga de esporos presentes, identificado os gêneros, bem como a umidade teor e $\mathrm{a}_{\mathrm{w}}$ das amostras (Tabela 1).

Carga fungica: No que diz respeito à carga fúngica, todas as amostras apresentaram crescimento, e como esperado, os esporos de fungos estavam presentes em $100 \%$ das amostras. A Tabela 1 apresenta quantificação da carga de fungos e identificação de gêneros isolados das amostras coletadas. O gênero Aspergillus predominou em todas as amostras. Condições controladas de armazenamento (baixa umidade e temperatura) tornam baixa a incidência de esporos de fungos contida em fenos. Entretanto, mesmo com umidade controlada (10-15\%) é possível observar aumento no número de esporos (Roberts, 1995).

Gênero isolados versus tipo de alimentação e armazenagem: os principais gêneros de fungos isolados e identificados nas amostras de feno, pasto e ração foram Aspergillus e Penicillium, (fungos de armazenagem), porém, em menor 
quantidade também o gênero Fusarium, (fungo de campo). Os fungos do gênero Aspergillus que apresentam velocidade de crescimento rápido, foram encontrados em todas as amostras de feno \& pasto, independentemente do local de armazenagem (entrada, aprisco, sala) e/ou coleta (galpão ou campo) sendo que as amostras de feno de alfafa possuíam cepas aflatoxigênicas. O que sugere a necessidade de um controle mais eficaz na aquisição de alimentos para os ovinos. Utilizando sementes de alfafa (Medicago sativa L.) em sua pesquisa Al-Askar et al. (2012) isoloaram gêneros de fungos Alternaria, Aspergillus, Penicillium e também Fusarium. Contudo, os Aspergillus e Alternaria foram os mais detectados.

Tabela 1. Contaminação fúngica em alimentos utilizados na dieta dos ovinos (feno, pasto e ração)

\begin{tabular}{|c|c|c|c|c|c|c|c|}
\hline \multirow{3}{*}{\multicolumn{2}{|c|}{ Alimentos para ovinos }} & \multicolumn{4}{|c|}{ Fungos } & \multirow{2}{*}{\multicolumn{2}{|c|}{ Umidade }} \\
\hline & & \multirow{2}{*}{$* \mathrm{UFC} / \mathrm{g}$} & \multicolumn{3}{|c|}{ Gênero } & & \\
\hline & & & Aspergillus & Penicillium & Fusarium & $\mathrm{mc}(\%)$ & $a_{w}$ \\
\hline \multicolumn{8}{|l|}{ Feno } \\
\hline \multirow[t]{3}{*}{$\overline{\text { Alfafa }}$} & Entrada do galpão & $0,3 \times 10^{4}$ & + & + & + & 12 & 0,5911 \\
\hline & Aprisco & $0,3 \times 10^{4}$ & + & ND & + & 12 & 0,6410 \\
\hline & Sala & $0,3 \times 10^{4}$ & + & ND & + & 12 & 0,5029 \\
\hline \multicolumn{8}{|l|}{ Pasto } \\
\hline \multicolumn{2}{|c|}{ B. decumbens } & $0,4 \times 10^{4}$ & + & ND & + & 40 & 0,9888 \\
\hline \multicolumn{8}{|c|}{ Ração } \\
\hline \multicolumn{2}{|c|}{ Milho e Soja } & $0,06 \times 10^{3}$ & + & $\mathrm{ND}$ & ND & 10 & 0,6497 \\
\hline
\end{tabular}

*Unidade formadora de colônias (7 dias $\left./ 25^{\circ} \mathrm{C}\right)$; + positivo; ND- não detectada.

As Figuras 1 e $\underline{2}$ apresentam as características da alimentação, bem como as estruturas reprodutivas dos gêneros Aspergillus e Penicillium isolados no feno, pasto e ração de ovinos. Importante salientar que os gêneros de fungos isolados podem ser de espécies toxigênicas, o que se confirmou, com a formação de fluorescência no meio de cultura das colônias dos respectivos gêneros (Figura 3 ).

Gêneros isolados versus tipo de alimentação e armazenagem: Os principais gêneros de fungos isolados e identificados nas amostras de feno, pasto e ração foram Aspergillus e Penicillium (fungos de armazenagem); porém, em menor quantidade também o gênero Fusarium (fungo de campo). Os fungos do gênero Aspergillus que apresentam velocidade de crescimento rápido foram encontrados em todas as amostras de feno \& pasto, independentemente do local de armazenagem (entrada, aprisco, sala) e/ou coleta (galpão ou campo) sendo que as amostras de feno de alfafa possuíam cepas aflatoxigênicas. $\mathrm{O}$ que sugere a necessidade de um controle mais eficaz na aquisição de alimentos para os ovinos. Utilizando sementes de alfafa (Medicago sativa L.) em sua pesquisa Al-Askar et al. (2012) isolaram gêneros de fungos Alternaria, Aspergillus, Penicillium e também Fusarium.
Contudo, os Aspergillus e Alternaria foram os mais detectados.

As Figuras 1 e 2 apresentam as características da alimentação, bem como as estruturas reprodutivas dos gêneros Aspergillus e Penicillium isolados no feno, pasto e ração de ovinos. Importante salientar que os gêneros de fungos isolados podem ser de espécies toxigênicas, o que se confirmou, com a formação de fluorescência no meio de cultura das colônias dos respectivos gêneros (Figura 3).

As AFLs são produzidas por algumas linhagens de fungos A. flavus, A. parasiticus e A. nomius, e causam grandes danos aos seres humanos e animais e uma das mais preocupantes, pois não são inativadas por aquecimento, como por exemplo, a pasteurização (Heathcote, 1984, Bruerton, 2001).

Toxigenicidade de cepas isoladas de alimentos para ovinos: após 7 dias de incubação das colônias isolados do feno/pasto e ração, foi possível detectar produção/formação de fluorescência no meio de cultura sob as colônias fúngicas frente à luz UV - 365nm (Figura 3). Além das alterações bromatológicas, o desenvolvimento de fungos pode prejudicar saúde dos animais e das pessoas que manuseiam os fenos, devido à produção de toxinas, principalmente aquelas relacionadas aos 
fungos toxigênicos do gênero Aspergillus. A alimentação com alta concentração de fungos e a exposição a esporos fúngicos pode ser prejudicial à saúde dos animais, especialmente em ruminantes jovens (Lowell, 1995).
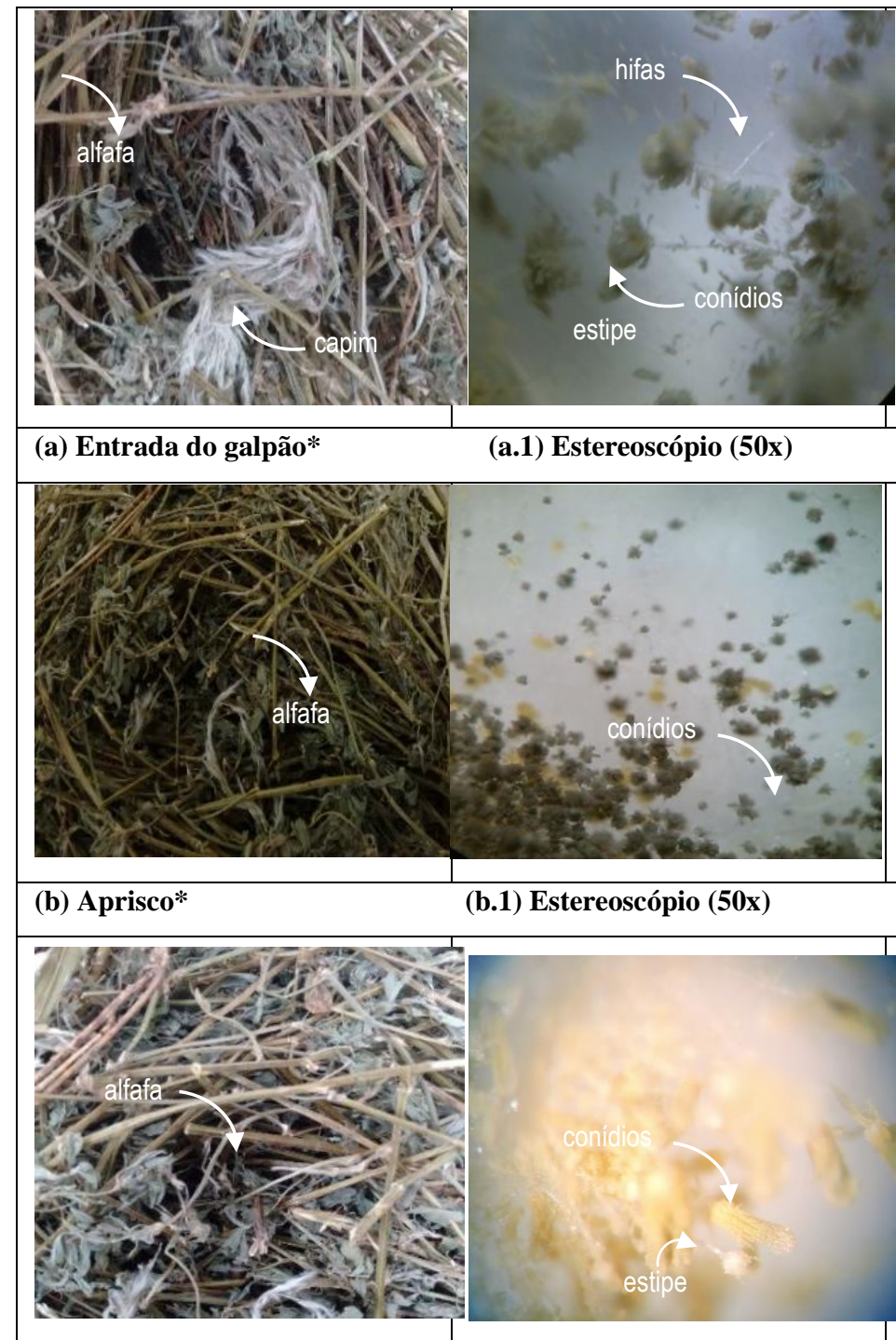

(c) Sala*

(c.1) Estereoscópio (50x)

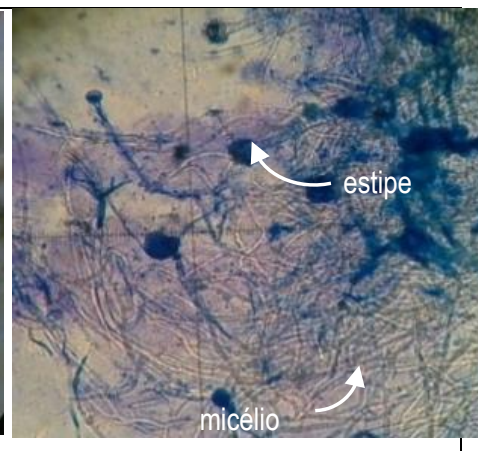

(a.2) Óptico (400x)

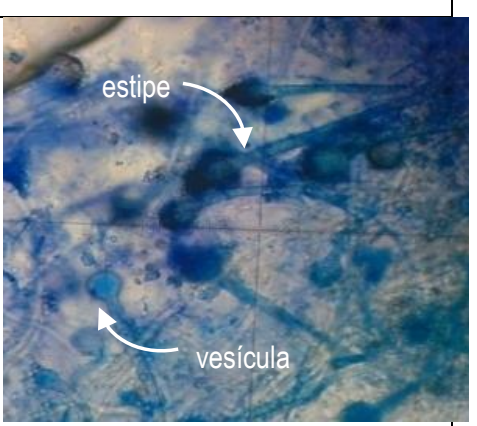

(b.2) Óptico (400x)

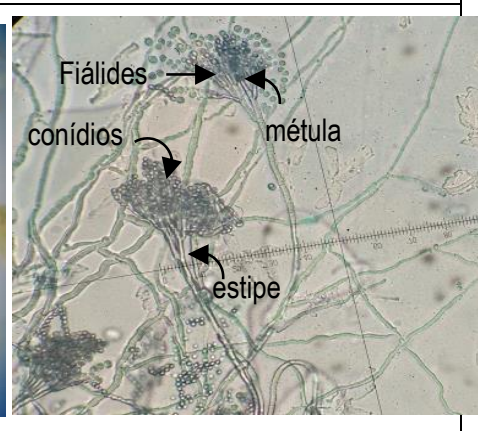

(c.2) Óptico (400x)

Figura 1. Características de alimentos para ovinos - FENO: (a/b/c) imagens macroscópicas e (a/b/c.1 e a/b/c.2) microscópicas de cepas contaminantes do gênero Aspergillus e Penicillium em microscópios estereoscópio e ótico [50 - 400x].* diferentes locais de armazenagem (entrada do galpão/aprisco/sala)

A presença de esporos está relacionada à uma doença respiratória em seres humanos chamada febre do feno. Nos animais, os distúrbios respiratórios não são intensos, com exceção dos equinos, que são acometidos problemas digestivos e respiratórios e causadas por fungos (Collins, 1995)

Umidade e atividade de água: os teores de umidade nas amostras de feno, pasto quanto ração armazenas e coletadas na região de Florianópolis, SC apresentaram-se elevados, e, portanto, propícios à proliferação de fungos (Tabela 1). De acordo com Albert et al. (1989), minimizar a atividade de água de alimentos reduz as taxas de alterações microbiológicas. $\mathrm{Na}$ fenação a forrageira é desidratada até atingir um teor de matéria seca que cesse a respiração celular e atividade de microrganismos indesejáveis a fim de impedir a deterioração da forragem. Com atividade da água de 1,0 e teor de umidade de (51,7-65,3\%), em feno de alfafa o crescimento fúngico foi caracterizado por um vasto desenvolvimento micelial. Reduzindo $\left(\mathrm{a}_{\mathrm{w}}\right)$ para 0,93 e mc $(28,1-41,7 \%)$, houve um aumento no desenvolvimento das estruturas de frutificação 
fúngica e reduzido crescimento micelial. Há hipóteses de que a maior produção de micotoxinas no feno (secado ao sol) está ligada á variação térmica diurna-noturna, que estimulou os fungos a produzir toxinas antes que a forragem atingisse um teor de umidade abaixo de 15\% (Albert et al., 1989).

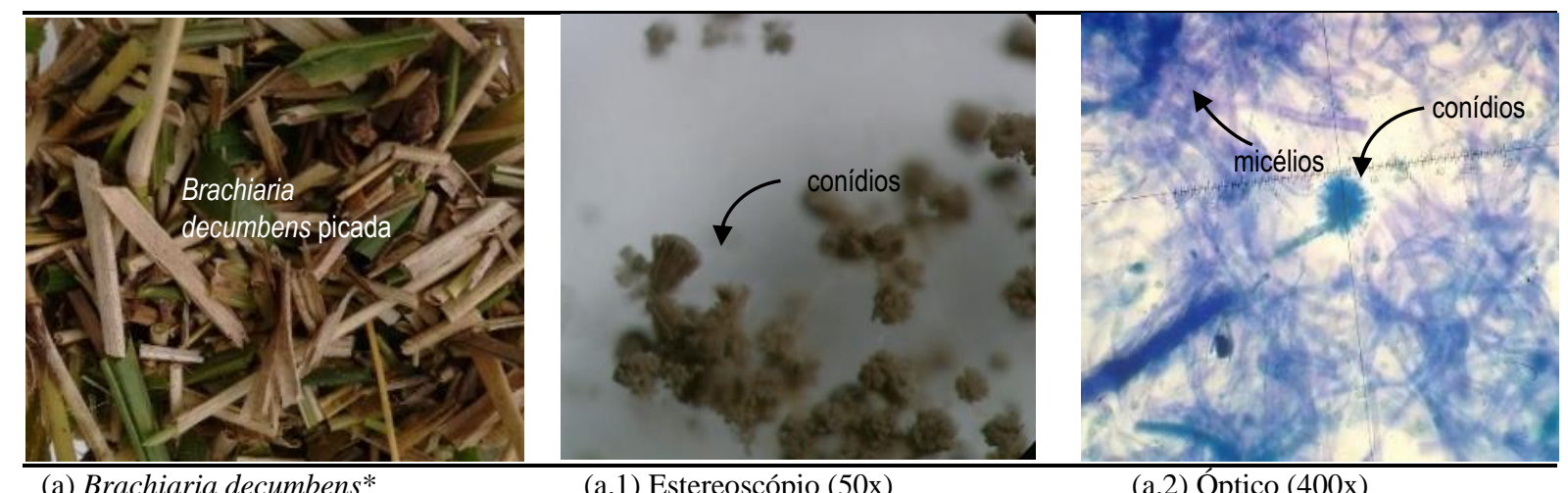

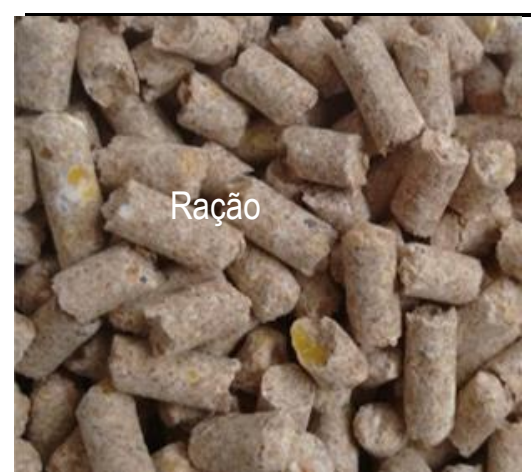

(b) Ração*

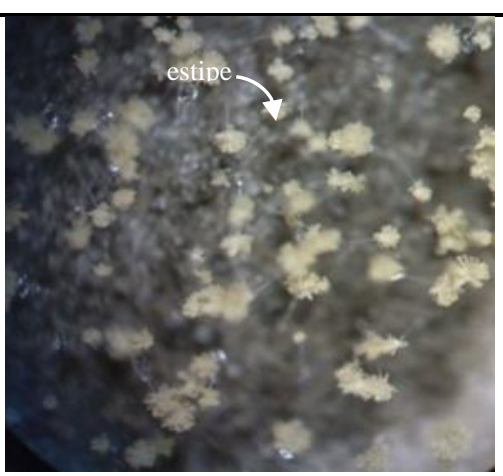

(b.1) Estereoscópio (50x)

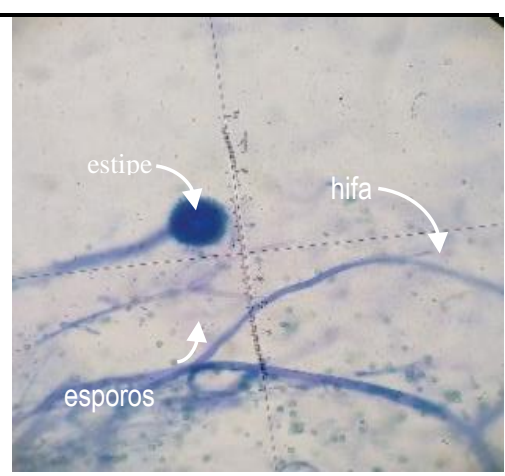

(b.2) Óptico (400x)

Figura 2. Características de alimentos para ovinos - PASTO: Brachiaria decumbens e RAÇão (a/b) imagens macroscópicas e (a/b.1 e a/b.2) microscópicas de cepas contaminantes do gênero Aspergillus em microscópios estereoscópio e ótico [50 - 400x].
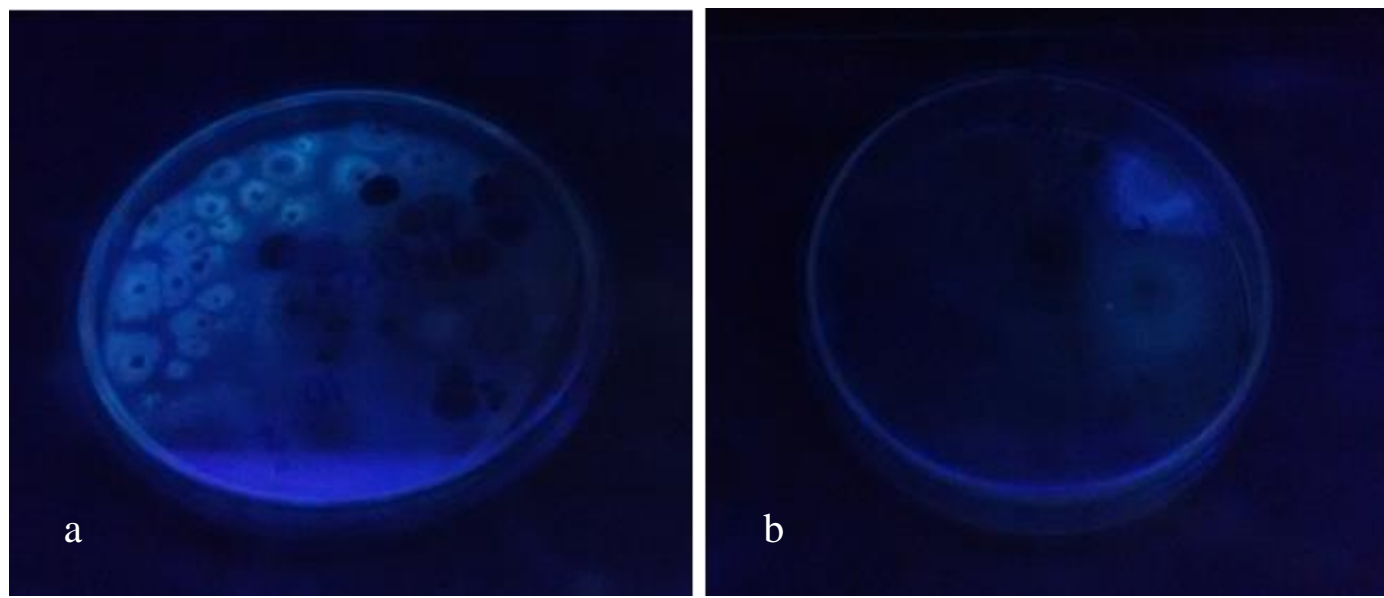

Figura 3. Microcultivo em meio de cultura (PDA) apresentando colônias de fungos toxigênicos provenientes de extrato de feno com cepas de fungos apresentando produção de aflatoxinas e sua fluorescência sob luz ultra violeta $(365 \mathrm{~nm})$ - (a) aprisco e (b) sala.

\section{Micotoxinas}

Quando as amostras de alimentos de ovinos foram analisadas para multitoxinas (AFLs, OTA, ZON, EST) foi possível registrar a presença de AFLs (Figura 4). Todas as amostras de feno apresentam contaminação por AFLs, independentemente do local, tempo de armazenagem e procedência. Inclusive as amostras que recém chegaram ao galpão, o que sugere que já estavam contaminadas no local de 
origem. As micotoxinas encontradas foram as de armazenagem AFLs, com teores de $128 \mu \mathrm{g} / \mathrm{kg}$. Consequentemente as amostras de feno apresentaram má qualidade com relação à contaminação pelas micotoxinas analisadas. Importante ressaltar que, as AFLs são produzidas especialmente por fungos de armazenagem (Aspergillus sp) e que se faz necessário nos períodos de armazenamento da alimentação para ovino, de um controle e monitoramento contínuo, para evitar que a haja proliferação de fungos com subsequente produção de metabólitos. Já nas amostras $B$. decumbens e ração não foram detectadas a presença de nenhuma toxina das avaliadas.

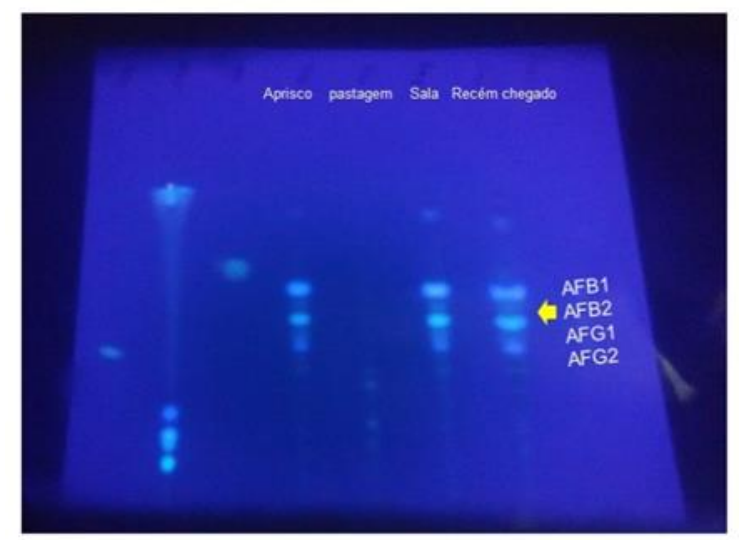

Figura 4. Cromatografia em camada delgada de extratos de feno e pasto sob luz UV evidenciando a presença de aflatoxinas $\left(\mathrm{AFB}_{1}, \mathrm{AFB}_{2}, \mathrm{AFG}_{1}, \mathrm{AFG}_{2}\right)$.

Sintomas dos ovinos versus micotoxinas detectadas: Döbereiner et al. (1976) registraram surtos em ovinos e bovinos (jovens e adultos) causados por Pithomyces charterem encontrado em pastagens de $B$. decumbens contaminadas. Os exames histopatológicos desses animais relataram ser intoxicação por agente hepatotóxico. Várias espécies de fungos toxigênicos representam um problema mundial para vários produtos agrícolas na pré e pós-colheita. Pavarini et al. (2009) pela administração de bagaço de malte (resíduo cervejaria) contaminado com Aspergillus clavatus para ovinos, constatou sinais clínicos, predominantemente locomotores e respiratórios, onde incluíam rigidez de membros pélvicos, tremores musculares, hiperestesia, taquipnéia, e decúbito. Contudo, o apetite e a dipsia estavam normais até próximo à morte ou eutanásia. Quando grãos de cevada contaminados por Aspergillus clavatus foram avaliados como responsáveis pela morte de ovinos, as manifestações clínicas relatadas foram: tremores, claudicação, locomoção anormal, paralisia e morte indicaram contaminação por micotoxicoses. Os achados patológicos foram limitados à degeneração neuronal e necrose no mesencéfalo (Shlosberg et al., 1991).

Em climas temperados, a silagem e as culturas forrageiras causam problemas ocasionais em animais. Entretanto, em países desenvolvidos micotoxinas não são consideradas um importante problema de saúde animal. Muitas vezes ocorrem problemas que vão da produtividade reduzida a mortes ocasionais. $\mathrm{O}$ reconhecimento das micotoxicoses é extremamente complexo, e o problema é exacerbado pela ausência de protocolos estruturados para a investigação de casos suspeitos. Sempre que houver indícios de que a micotoxina possam estar presentes em produtos de origem animal, devem ser considerados riscos de transferência para o homem.

\section{Conclusão}

Mesmo com a armazenagem correta do feno (em locais aparentemente secos - sala de armazenagem), possuem condições favoráveis para a proliferação de fungos e consequentemente o surgimento de micotoxinas.

A contagem fúngica foi elevada e as amostras apresentaram número de colônias semelhantes, quando comparadas com a pastagem de $B$. decumbens e ração devido ao elevado teor de umidade.

As condições de limpeza dos maquinários durante a colheita do feno e dos locais de armazenam ainda no campo são de extrema importância, uma vez que as amostras recémchegadas ao local de abrigo das ovelhas se encontram contaminadas.

Os sintomas desencadeados nos animais em estudo foram semelhantes aos produzidos pelas toxinas encontradas nos fenos (Aflatoxinas).

\section{Referências Bibliográficas}

Al-Askar, A.-A. A., Ghoneem, K. M. \& Rashad, Y. M. 2012. Seed-borne mycoflora of alfalfa (Medicago sativa L.) in the Riyadh Region of Saudi Arabia. Annals of Microbiology, 62, 273-281.

Albert, R. A., Huebner, B. \& Davis, L. W. 1989.

Role of water activity in the spoilage of alfalfa hay. Journal of Dairy Science, 72, 2573-2581. 
AOAC. 2005. - Association Official Analytical Chemist (2005), Official Methods of Analysis (18th ed.) edn. AOAC, Gaitherburg, Maryland, USA.

Bruerton, K. 2001. Finding practical solutions to mycotoxins in commercial production: a nutritionist's perspective. Alltech's 17th Annual Symposium.

Collins, M. 1995. Hay preservation effects on yield and quality. In: Moore, K. J., Kral, D. M. \& Viney, M. K. (eds.) Post-harvest physiology and preservation of forages. American Society of Agronomy, Madison.

Döbereiner, J., Tokarnia, C. H., Monteiro, M. C. C., Cruz, L. C. H., Carvalho, E. G. \& Primo, A. T. 1976. Intoxicação de bovinos e ovinos em pastos de Brachiaria decumbens contaminados por Pithomyces chartarum. Pesquisa Agropecuária Brasileira, 11, 87-94.

Edrington, T. S., Harvey, R. B. \& Kubena, L. F. 1994. Effect of aflatoxin in growing lambs fed ruminally degradable or escape protein sources. Journal of Animal Science, 72, 12741281.

Fonseca, H. 2008. Micotoxinas e problemas associados versus qualidade fungos.2008. In: Scussel, V. M. (ed.) Atualidades em micotoxinas e armazenagem de grãos. Florianópolis, Santa Catarina.

Gallo, A., Giuberti, G., Frisvad, J. C., Bertuzzi, T. \& Nielsen, K. F. 2015. Review on mycotoxin issues in ruminants: occurrence in forages, effects of mycotoxin ingestion on health status and animal performance and practical strategies to counteract their negative effects. Toxins, 7, 3057-3111.

Heathcote, J. G. 1984. Aflatoxins and related toxins. Developments in Food Science.

Iamanaka, B. T., Oliveira, I. S. \& Taniwaki, M. H. 2013. Micotoxinas em alimentos. Anais da Academia Pernambucana de Ciência Agronômica, 7, 138-161.

Lowell, M. E. 1995. Post-harvest physiological changes in forage plants. In: Moore, K. J., Kral, D. M. \& Viney, M. K. (eds.) Post-harvest physiology and preservation of forages. American Society of Agronomy, Madison.

Mallmann, C. A., Santurio, J. M. \& Wentz, I. 1994. Aflatoxinas-Aspectos clínicos e toxicológicos em suínos. Ciência Rural, 24, 635-643.
Nascimento, J. M., Costa, C., Silveira, A. C. \& Arrigoni, M. D. B. 2000. Influência do método de fenação e tempo de armazenamento sobre a composição bromatológica e ocorrência de fungos no feno de alfafa (Medicago sativa, L. cv. Flórida 77). Revista Brasileira de Zootecnia, 29, 669-677.

Pavarini, S. P., Bezerra Junior, P. S., Santos, A. d. S., Bandarra, P. M., Pedroso, P. M. O., Spanamberg, A., Driemeier, D. \& Ferreiro, L. 2009. Intoxicação experimental por Aspergillus clavatus em ovinos. Pesquisa Veterinária Brasileira, 29, 205-210.

Pitt, J. I. 1979. The genus Penicillium and its teleomorphic states Eupenicillium and Talaromyces. Academic Press, Londo, UK.

Rabassa, V. R., Schwegler, E., Goulart, M. A., Lopes, M. S., Hoffmann, D. A., Lisboa, F. P., Vendramin, L., Roll, V. F. B., Diaz, G. J. \& Del Pino, F. A. B. 2010. Parâmetros metabólicos de ovelhas submetidas a dietas contendo aflatoxina e zearalenona com adição de glucomanano modificado. Brazilian Journal of Veterinary Research and Animal Science, 47, 67-73.

Raper, K. B. \& Fennell, D. I. 1965. The genus Aspergillus. Baltimore.

Roberts, C. A. 1995. Microbiology of stored forrages. In: Moore, K. J. \& Peterson, M. A. (eds.) Post-harvest physiology and preservation of forages. Crop Science Society of America and American Society of Agronomy, USA.

Santos, M. C., Sousa, R. B., de Oliveira, S. E. M., Lima, K. S. C. \& Lima, A. L. S. 2014. Micotoxinas e seu potencial como agentes de guerra. Revista Virtual de Química, 6, 761-778.

Scussel, V. M. 1998. Micotoxinas em alimentos. Insular, São Paulo.

Scussel, V. M. \& Lorini, I. 2002. Fungos em grãos armazenados. In: Lorini, I., Miike, L. H. \& Scussel, V. M. (eds.) Armazenagem de grãos. Campinas. IBG, Campinas - São Paulo.

Shlosberg, A., Zadikov, I., Perl, S., Yakobson, B., Varod, Y., Elad, D. \& Handji, V. 1991. Aspergillus clavatus como a causa provável de uma neurotoxicose em massa letal em ovinos. Mycopathologia, 114, 35-39.

Silva, N., Neto, R. C., Junqueira, V. C. A. \& Silveira, N. F. A. 2005. Manual de Métodos de Análise Microbiológica de Alimentos e da Água. Varela, Campinas, São Paulo, Brazil. 
Soares, L. M. \& Rodriguez-Amaya, D. B. 1989. Survey of aflatoxins, ochratoxin A, zearalenone, and sterigmatocystin in some Brazilian foods by using multi-toxin thin-layer chromatographic method. Journal-Association of Official Analytical Chemists, 72, 22-26.

Wambacq, E., Vanhoutte, I., Audenaert, K., Gelder, L. \& Haesaert, G. 2016. Occurrence, prevention and remediation of toxigenic fungi and mycotoxins in silage: A review. Journal of the Science of Food and Agriculture, 96, 22842302.

\section{Article History:}

Received 24 July 2017

Accepted 18 August 2017

Available on line 17 October 2017

License information: This is an open-access article distributed under the terms of the Creative Commons Attribution License 4.0, which permits unrestricted use, distribution, and reproduction in any medium, provided the original work is properly cited. 